УДК 542.06.542.61.542.46.808.542.97.542.93

\title{
МАСС-СПЕКТРОМЕТРИЯ СУПРАМОЛЕКУЛЯРНЫХ КОМПЛЕКСОВ ГЛИЦИРРЕТИНОВОЙ КИСЛОТЫ С АНТИБИОТИКОМ СТРЕПТОЦИДОМ
}

\author{
() С.Н. Борисенко, Е.В. Ветрова, А.В. Лекарь, О.В. Филонова, Н.И. Борисенко \\ НИИ фризической и органической химии Южного фредерального \\ университета, пр. Стачки, 194/2, Ростов-на-Дону, 344090 (Россия), \\ e-mail: boni@ipoc.rsu.ru
}

Один из эффективных путей для увеличения биодоступности лекарственных субстанций заключается в их структурной модификации путем формирования супрамолекулярных структур с участием растительных гликозидов. Использование нековалентных комплексов фармаконов с растительными гликозидами, например глицирризиновой кислотой (ГК), выделенной из корней солодки голой Glycyrrhiza glabra L., приводит к существенному улучшению фармакокинетических и фармакодинамических показателей лекарственных веществ. Широким спектром биологической активности обладает глицирретиновая кислота (ГЛК), которая является агликоном ГК и имеет аналогичный с ней молекулярный скелет. Целью представленной работы является изучение комплексообразования ГЛК с антимикробными препаратами для создания новых низкодозных фармсубстанций. В представленной работе впервые синтезированы комплексные соединения ГЛК и антибиотика стрептоцида (СТР) при различных соотношениях концентраций «хозяина» и «гостя». Методом масс-спектрометрии с ионизацией электрораспылением продемонстрировано формирование супрамолекулярных комплексов ГЛК с СТР. Масс-спектры показывают наличие пиков ионов разнообразных по составу гетерогенных комплексов, состоящих из мономеров, димеров, тримеров и тетрамеров ГЛК с включением одной молекулы СТР. Установлено, что процессы самоассоциации ГЛК являются конкурирующими процессам образования гетерогенных нековалентных комплексов. Результаты исследований демонстрируют высокую биологическую активность ГЛК при связывании СТР в растворе с образованием супрамолекулярных комплексов, показывают возможности синергетических эффектов и открывают перспективы в получении новых низкодозных лекарственных форм.

Ключевые слова: глицирретиновая кислота, глицирризиновая кислота, стрептоцид, масс-спектрометрия, ионизация электрораспылением, комплексообразование; супрамолекулярные комплексы.

Работа выполнена при финансовой поддержке грантов РФФИ 13-03-01318 и 13-03-12271 офи_м.

\section{Введение}

Известно, что одним из перспективных путей разработки новых лекарственных форм на основе вторичных растительных метаболитов является связывание исследуемых веществ в супрамолекулярные комплексы с целью получения низкодозных лекарственных субстанций. В качестве полидентантных лигандов при синтезе этих комплексов широко используются растительные сапонины. В частности, в Российской

Борисенко Сергей Николаевич - старший научный сотрудник, кандидат химических наук, e-mail: sn.borisenko@gmail.com

Ветрова Елена Владимировна - старший научный сотрудник, кандидат биологических наук, e-mail: vetrova@ipoc.sfedu.ru Лекарь Анна Владимировна - младший научный сотрудник, e-mail: lekarann@mail.ru Филонова Ольга Владимировна - младший научный сотрудник, e-mail: fokysnik007@mail.ru Борисенко Николай Иванович - главный научный сотрудник, кандидат химических наук, e-mail: boni@ipoc.rsu.ru Федерации активно ведутся работы по созданию низкодозных лекарственных субстанций на основе глицирризиновой кислоты и хорошо апробированных фармсубстанций - фармаконов (в терминах школы академика Г.А. Толстикова) [1-3]. В работах российских ученых показано, что субстанции, полученные на основе глицирризиновой кислоты, обеспечивают уменьшение эффективных доз лекарственных препаратов в 100-200 раз [3, 4]. В таких супрамолекулярных комплексах моле-

\footnotetext{
*Автор, с которым следует вести переписку.
} 
кулы глицирризиновой кислоты выступают в роли полидентантных лигандов, образующих с фармаконами супрамолекулярные комплексы различной стехиометрии.

Для установления фундаментальных связей структура - свойства важно изучение механизмов образования таких комплексов по типу «хозяин - гость», где сапонин, в качестве молекулы-«хозяина», может образовывать в гидрофильной среде эндолипофильную полость для молекулы «гостя» [5]. Ранее авторами с использованием квантовохимических расчетов и масс-спектрометрии показано [5], что молекулы глициризиновой кислоты образуют устойчивые самоассоциаты кластеров общего вида Xn (n=6). Отмечено, что при этом самоассоциаты глицирризиновой кислоты, образующиеся из двух и более молекул глицирризиновой кислоты, имеют полость между ними, достаточную для включения соразмерных молекул-«гостей». Последнее было подтверждено методом масс-спектрометрии с ионизацией электрораспылением на примере супрамолекулярных комплексов глицирризиновой кислоты с производными бензамидазола [6].

Глицирретиновая кислота (ГЛК) является агликоном и основным метаболитом глицирризиновой кислоты. Почти полностью растворяется в хлороформе, горячем 95\%-ном спирте, при добавлении в спирт воды до 40\% ГЛК выпадает в осадок в виде мелкокристаллического осадка. Характерно, что природная ГЛК является 18ß-изомером, обладающим биологической активностью [7]. ГЛК обладает противовоспалительными [8], противоязвенными, противоаллергическими, противовирусными, антибактериальными [9] и гепатопротекторными свойствами [10]. Глицирретиновая кислота ингибирует фермент $11 \beta$-гидрокси-стероидов дегидрогеназы второго типа, что способствует снижению концентрации калия в сыворотке крови [11]. Недавние исследования показали, что биотинилированная глицирретиновая кислота обладает противоопухолевой активностью, что подтверждено посредством испытаний на мышах (клетки меланомы B16) и BEL 7402 (клетки гепатокарциномы человека) [12]. Авторы [13] выявили, что 18ß-глицирретиновая кислота способна снизить гипергликемию и гиперлипидемию, связанные с риском возникновения сахарного диабета. In vitro также показана активность глицирретиновой кислоты в отношении Helicobacter pylori [14].

Можно предположить, что стереоизомеры глицирретиновой кислоты по аналогии с сапонинами солодки [6] и плюща [15-16] могут стать потенциальной основой для синтеза нового поколения нековалентных молекулярных комплексов и новых высокоэффективных лекарственных субстанций - как за счет возможного улучшения биодоступности [2], так и за счет возможных синергетических эффектов [17]. Основанием для развития такого направления служит то, что недавно авторами [18] на примере стереоизомеров глицирретиновой кислоты показано, что оба стереоизомера ГЛК по аналогии с тритерпеновыми сапонинами формируют автоассоциаты, причем устойчивость этих супрамолекулярных комплексов достаточна для преодоления кулоновского отталкивания.

Цель представленной работы - продолжение работ по изучению комплексообразования биологически активных вторичных растительных метаболитов с антимикробными препаратами для создания новых низкодозных фармсубстанций на основе агликона глицирризиновой кислоты. В представленной работе впервые синтезированы и изучены методом масс-спектрометрии с ионизацией электрораспылением комплексные соединения глицирретиновой кислоты и антибиотика стрептоцида, синтезированные при различных соотношениях концентраций «хозяина» и «гостя».<smiles>CC1(C(=O)O)CCC2(C)CCC3(C)C(=CC2=O)C2CC(C)(C(=O)O)C4CCC5(C)C(CCC(O)C5(C)C)C4(C)C23C1</smiles>

Глицирретиновая кислота (ГЛК) $(\mathrm{M}=470,68)$

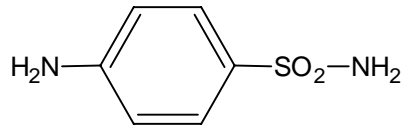

Стрептоцид (СТР)

$(\mathrm{M}=172,22)$

Стрептоцид - сульфаниламидный препарат, относящийся к группе химиотерапевтических препаратов с избирательным бактериостатическим действием по отношению к стрептококкам, менингококкам, гонококкам, пневмококкам, кишечной палочке и некоторым другим бактериям. Противомикробная активность стрептоцида и других сульфаниламидных препаратов обусловлена их бактериостатическим действи- 
ем на возбудителей инфекционных заболеваний, т.е. их способностью подавлять размножение микробов, что обуславливает их широкое использование в медицине.

\section{Экспериментальная часть}

Глицирретиновая кислота приобретена в Aldrich Sigma, стрептоцид белый (CTP) куплен в розничной аптечной сети «Социальная аптека». Для синтеза комплексов и прямого ввода были использованы растворы в метаноле (Merk, квалификация HPLC/MS) в концентрации до 0,1 мг/мл $\left(10^{-7}-10^{-6} \mathrm{M}\right)$.

Получение комплексов включения ГЛК и СТР проводили в молярном соотношении $1: 1$ и $4: 1$ соответственно. Навески ГЛК и стрептоцида (взвешенные с точность 0,001 г) засыпали в коническую колбу с 7 мл метанола. Содержимое перемешивали на магнитной мешалке при температуре до $50{ }^{\circ} \mathrm{C}$ в течение 2 ч.

Полученные смеси анализировали на содержание комплексов методом масс-спектрометрии на приборе Bruker Daltonics micrOTOF-Q с ионизацией электрораспылением. Программное обеспечение micrOTOFcontrolTM 2.2. Калибровочный раствор фирмы Fluka (Electrospray Calibrant Solution). Детектирование отрицательных и положительных ионов осуществлялось в интервале от 50 до 3000 Да с точностью не менее $1 \times 10^{-2}$ Да. Напряжение на капилляре распылителя $\pm 3500 \mathrm{~B}$, параметры газа-осушителя - азот «осч», 5 л/мин, $180^{\circ} \mathrm{C}$, энергия ионов на квадруполе $-5,0$ эВ.

\section{Обсуждение результатов}

Для изучения строения супрамолекулярных комплексов получена серия масс-спектров образцов супрамолекулярных комплексов глицирретиновой кислоты и фармакона (стрептоцида) при различных мольных соотношениях «хозяин - гость» $(1: 1$ и $4: 1)$. В данном случае в роли «хозяина», определяющего формирование супрамолекулярной структуры, использовали ГЛК.

В масс-спектрах исследованных образцов зарегистрированы пики, принадлежащие ионам молекул ГЛК и протонированным мономерам антибиотика СТР, и пики, отвечающие разнообразным комплексам, состоящим из мономеров, димеров, триммеров, тетрамеров и пентамеров ГЛК с включением одной молекулы СТР (табл.).

В таблице представлены параметры масс-спектров для мономеров, димеров ГЛК, регистрируемых в стандартном растворе ГЛК, а также в исследованных образцах со СТР.

Характерные ионы в масс-спектрах глицирретиновой кислоты (ГЛК), стрептоцида (СТР) и их комплексов $(1: 1$ и $4: 1)$

\begin{tabular}{|c|c|c|c|c|}
\hline $\mathrm{m} / \mathrm{z}$ & Строение иона & $\mathrm{I}_{\text {станд }}, \%$ & $\mathrm{I}_{1: 1}, \%$ & $\mathrm{I}_{4: 1}, \%$ \\
\hline \multicolumn{5}{|c|}{ Стрептоцид (СТР) $(\mathrm{Mw}=172,22)$} \\
\hline 173,08 & {$\left[\mathrm{M}^{\mathrm{CTP}}+\mathrm{H}\right]^{+}$} & 2,10 & 8,25 & 1,04 \\
\hline 195,06 & {$\left[\mathrm{M}^{\mathrm{CTP}}+\mathrm{Na}\right]^{+}$} & 100 & 69,37 & 9,16 \\
\hline 367,32 & {$\left[2 \mathrm{M}^{\mathrm{CTP}}+\mathrm{Na}\right]^{+}$} & 7,22 & 2,95 & 0,53 \\
\hline \multicolumn{5}{|c|}{ Глицирретиновая кислота (ГЛК) $((\mathrm{Mw}=470,68)$} \\
\hline 471,44 & {$\left[\mathrm{M}^{\mathrm{TJK}}+\mathrm{H}\right]^{+}$} & 100 & 98,54 & 81,75 \\
\hline 493,42 & {$\left[\mathrm{M}^{\Gamma л \kappa}+\mathrm{Na}\right]^{+}$} & 46,88 & 100 & 100 \\
\hline 509,40 & {$\left[\mathrm{M}^{\Gamma Л \kappa}+\mathrm{K}\right]^{+}$} & 16,64 & 65,66 & 26,36 \\
\hline 267,73 & {$\left[\mathrm{M}^{\Gamma л \kappa}+\mathrm{K}+\mathrm{Na}\right]^{2+}$} & 2,43 & 1,96 & 4,10 \\
\hline 941,87 & {$\left[2 \mathrm{M}^{\Gamma Л \kappa}+\mathrm{H}\right]^{+}$} & 36,59 & 28,84 & 21,75 \\
\hline 979,83 & {$\left[2 \mathrm{M}^{\Gamma л \kappa}+\mathrm{K}\right]^{+}$} & 8,13 & 19,39 & 5,04 \\
\hline 509,41 & {$\left[2 \mathrm{M}^{\Gamma Л К}+2 \mathrm{~K}\right]^{2+}$} & 3,47 & 65,66 & 26,36 \\
\hline 963,85 & {$\left[2 \mathrm{M}^{\text {ГЛК }}+\mathrm{Na}\right]^{+}$} & 19,71 & 38,00 & 30,71 \\
\hline \multicolumn{5}{|c|}{ Супрамолекулярные комплексы (ГЛК : СТР) } \\
\hline 665,50 & {$\left[\mathrm{M}^{\mathrm{\Gamma JK}}+\mathrm{M}^{\mathrm{CTP}}+\mathrm{Na}\right]^{+}$} & & 52,91 & 10,33 \\
\hline 1135,93 & {$\left[2 \mathrm{M}^{\text {ГЛК }}+\mathrm{M}^{\mathrm{CTP}}+\mathrm{Na}\right]^{+}$} & & 4,45 & 1,09 \\
\hline 803,67 & {$\left[3 \mathrm{M}^{\Gamma Л \mathrm{~K}}+\mathrm{M}_{2+}^{\mathrm{CTP}}+\mathrm{Na}+\mathrm{H}\right]$} & & 1,13 & - \\
\hline 814,69 & {$\left[3 \mathrm{M}^{\text {ГлК }}+\mathrm{M}^{\mathrm{CTP}}+2 \mathrm{Na}\right]^{2+}$} & & 1,62 & - \\
\hline 1049,91 & {$\left[4 \mathrm{M}^{\text {ГЛК }}+\mathrm{M}^{\mathrm{CTP}}+2 \mathrm{Na}\right]^{2+}$} & & 2,30 & 1,00 \\
\hline 1284,09 & {$\left[5 \mathrm{M}^{\text {ГЛК }}+\mathrm{M}^{\mathrm{CTP}}+2 \mathrm{Na}\right]^{2+}$} & & 0,30 & 0,20 \\
\hline
\end{tabular}


Как видно из таблицы, стрептоцид в режиме положительных ионов ионизируется с образованием аддукта с натрием $\left[\mathrm{M}^{\mathrm{CTP}}+\mathrm{Na}\right]^{+}$и в масс-спектре представлен пиком $m / z$ 194,91. Также зарегистрирован пик димера стрептоцида $\left[2 \mathrm{M}^{\mathrm{CTP}}+\mathrm{Na}\right]^{+} \mathrm{c} m / z$ 366,89. Стрептоцид в масс-спектрах представлен пиком с $m / z, 173,08$ протонированного иона $\left[\mathrm{M}^{\mathrm{CTP}}+\mathrm{H}\right]^{+}$, но интенсивность пика была существенно ниже, чем для аддуктов с натрием. Для идентифицированных ионов СТР наблюдали уменьшение интенсивности пиков с ростом концентрации ГЛК в образце, что указывает на уменьшение СТР в свободном состоянии.

В масс-спектре положительных ионов стандартного раствора ГЛК основной пик принадлежит протонированной молекуле ГЛК с $m / z$ 471,44. Помимо этого, присутствует изохорная группа пиков для однои двузарядных ионов ГЛК. Так, формирование однозарядного катиона с натрием $\mathrm{m} / z$ 493,43 происходит в 2,8 раза эффективнее, чем с калием $m / z$ 509,41. Здесь интересно отметить, что, как уже ранее сообщалось авторами [18], в режиме регистрации положительных ионов наблюдается широкий спектр ионов - самоассоциатов ГЛК. Например, регистрируются пики протонированного иона димера ГЛК с $\mathrm{m} / z \quad 941,87$ $\left[2 \mathrm{M}^{\text {ГлК }}+\mathrm{H}\right]^{+}$и катионизированного ионом натрия димера ГЛК с $m / z, 963,85\left[2 \mathrm{M}^{\Gamma л К}+\mathrm{Na}\right]^{+}$.

Из таблицы видно, что при переходе к масс-спектрам синтезированных комплексов ГЛК с СТР основным пиком в масс-спектрах положительных ионов является пик катионизированного натрием иона ГЛК

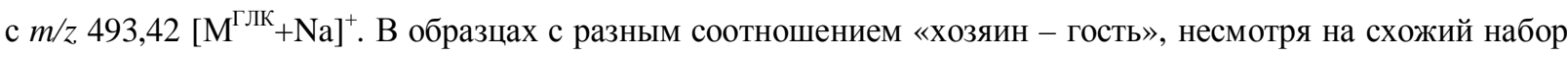
значений $m / z$ в масс-спектре, величины интенсивностей соответствующих пиков существенно изменялись. Так, интенсивность пика для катионизированной $\mathrm{Na}^{+}$молекулы СТР с $m / z$ 194,91, [M $\left.{ }^{\mathrm{CTP}}+\mathrm{Na}\right]^{+}$на $30 \%$ меньше $(69,37 \%)$ при соотношении 1:1. Увеличение мольной доли ГЛК привело к дальнейшему уменьшению относительной интенсивности пиков мономеров и димеров СТР. Масс-спектры положительных ионов полученных комплексов ГЛК и СТР представлены на рисунке. При этом относительная интенсивность пика $\mathrm{m} / \mathrm{z}$ 173,08 протонированного мономера свободного стрептоцида значительно снизилась и составила $1,04 \%$ при соотношении $4: 1$, по сравнению с 8,25\% при соотношении концентраций «хозяин - гость» $1: 1$, что обусловлено увеличением вероятности включения фармакона в комплексы с ГЛК.

Интенсивность пиков самоассоциатов ГЛК значительно выше, чем интенсивности пиков соответствующих супрамолекулярных комплексов ГЛК с СТР, что указывает, вероятно, на большую эффективность процессов самоассоциации по сравнению с процессом образования супрамолекулярных комплексов. Так, относительная интенсивность пика с $m / z$ 665,50, соответствующая комплексу $\left[\mathrm{M}^{\text {Глк }}+\mathrm{M}^{\mathrm{CTP}}+\mathrm{Na}\right]^{+}$, уменьшается с 52,91 до 10,33\%, тогда как интенсивность пика $m / z$ 941,87 димера $\left[2 \mathrm{M}^{\Gamma л \kappa}+\mathrm{H}\right]^{+}$оказывается практически неизменной - 28,84 и 21,75\% соответственно при переходе от концентраций $1: 1$ к концентрациям $4: 1$.

Комплексообразование ГЛК со СТР представлено в масс-спектрах положительных ионов достаточно широко. Идентифицированы пики катионизированных $\mathrm{Na}^{+}$ионов, соответствующие комплексам с соотношением «хозяин - гость» $1: 1 ; 2: 1 ; 3: 1 ; 4: 1$ и $5: 1$. Связывание мономерами и самоассоциатами ГЛК одной молекулы СТР наиболее полно представлено в образце с соотношением «хозяин - гость» $1: 1$. С наибольшей интенсивностью пика, следовательно, и с большей вероятностью происходит взаимодействие мономеров ГЛК и СТР. Интенсивность пика $m / z, 665,50$ для $\left[\mathrm{M}^{\text {ГлК }}+\mathrm{M}^{\mathrm{CTP}}+\mathrm{Na}\right]^{+}$в образце $1: 1$ составила 52,91\%. Комплексообразование многомерных самоассоциатов (n > 2) ГЛК с СТР представлено пиками меньшей интенсивности (до 5\%), что обусловлено меньшей вероятностью существования таких ассоциатов ГЛК.

Необходимо отметить, что идентифицированы комплексы в виде катионизированных $\mathrm{Na}^{+}$ионов. Ранее при исследовании процессов самоассоциации молекул ГЛК также отмечена важная роль катионов в образовании самоассоциатов. Вероятно, в процессы самоассоциации и комплексообразования с участием ГЛК особую роль играют электростатические взаимодействия.

Представленные результаты указывают на высокий потенциал молекул ГЛК в связывании фармаконов, и демонстрируют высокую биологическую активность ГЛК и возможности синергетических эффектов [17], а также открывают перспективы в получении новых лекарственных форм. 

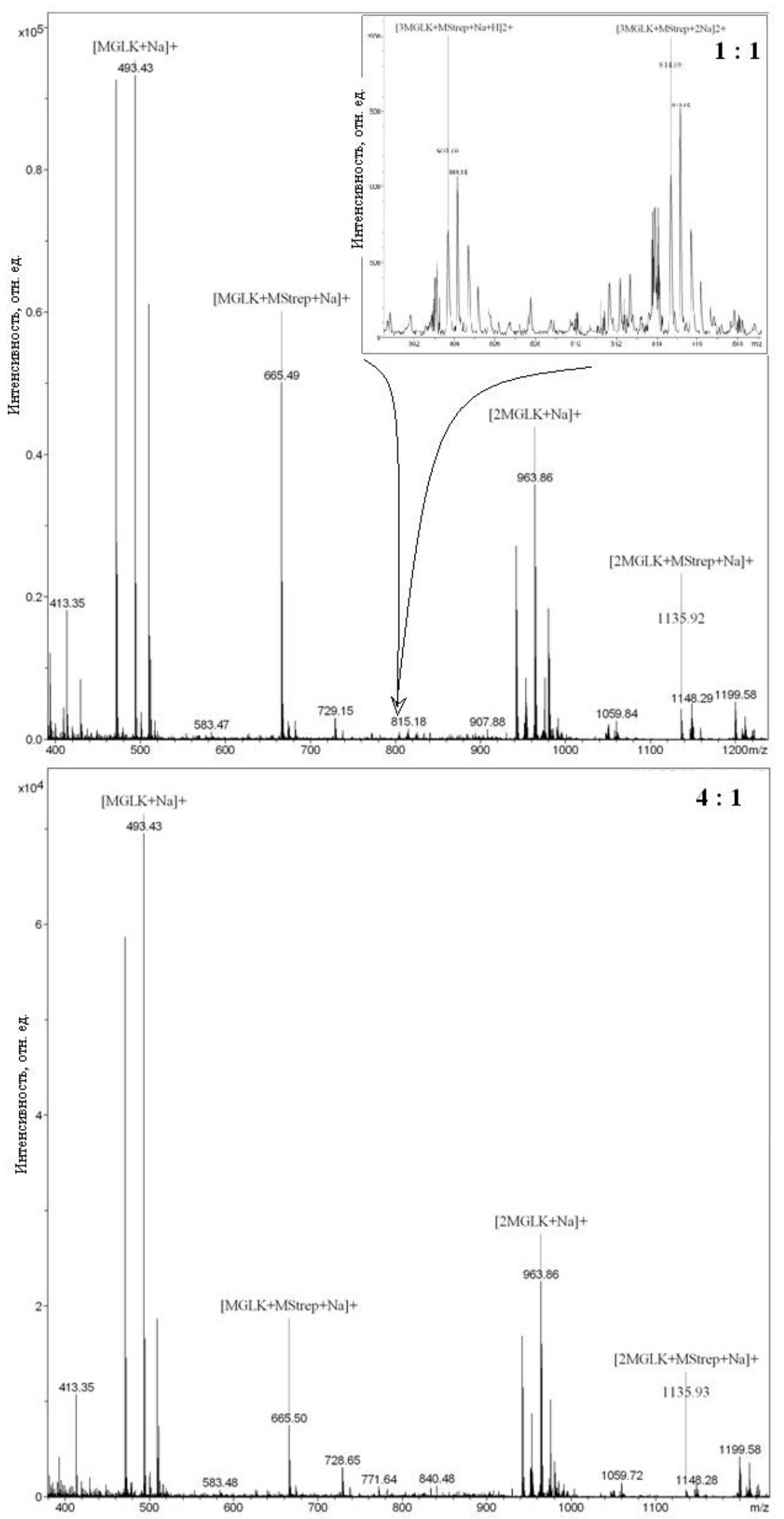

Масс-спектр положительных ионов супрамолекулярных комплексов ГЛК и СТР при соотношении «хозяин - гость» $1: 1$ (верху) и $4: 1$ (внизу) 


\section{Заключение}

Таким образом, с помощью масс-спектрометрии с ионизацией электрораспылением зарегистрировано формирование супрамолекулярных комплексов с участием мономеров и самоассоциатов ГЛК с включением одной молекулы СТР.

Масс-спектры комплексов, полученных при различных соотношениях концентраций «хозяин гость», показывают наличие пиков ионов разнообразных по составу супрамолекулярных комплексов состоящих из мономеров, димеров, тримеров и тетрамеров глицирретиновой кислоты с включением одной молекулы антибиотика стрептоцида.

Полученные результаты демонстрируют высокую активность ГЛК при связывании СТР в растворе с образованием новой формы лекарственного препарата, что может приводить как к изменению его биологического действия, так и к снижению побочных эффектов при его использовании.

Метод масс-спектрометрии с ионизацией электрораспылением обеспечивает прямой мониторинг макроскопического состава самоорганизующихся систем. Применение метода позволяет получить качественную картину присутствующих супрамолекулярных видов.

\section{Список литературы}

1. Толстиков Г.А., Балтина Л.А., Шульц Э.Э., Покровский А.Г. Глицирризиновая кислота // Биоорганическая химия. 1997. Т. 23, №9. С. 691-703.

2. Толстикова Т.Г., Толстиков А.Г., Толстиков Г.А. На пути к низкодозным лекарствам // Вестник Российской академии наук. 2007. Т. 77, №10. С. 867-874.

3. Стоник В.А., Толстиков Г.А. Природные соединения и создание отечественных лекарственных препаратов // Вестник Российской академии наук. 2008. Т. 78, №8. С. 675-684.

4. Толстикова Т.Г., Сорокина И.В., Брызгалов А.О., Лифшиц Г.И., Хвостов М.В. Использование подхода комплексообразования с глицирризиновой кислотой для создания новых кардиотропных средств // Биомедицина. 2006. T. 1, №4. C. 115-116.

5. Борисенко С.Н., Лекарь А.В., Милов А.А., Ветрова Е.В., Борисенко Н.И. Масс-спектрометрия и квантовохимическое исследование процессов самоассоциации молекул глицирризиновой кислоты // Химия растительного сырья. 2013. №2. С. 85-92.

6. Borisenko S.N., Lekar A.V., Vetrova E.V., Borisenko N.I. Mass spectrometry of supramolecular complexes of glycyrrhizic acid and benzimidazole derivatives // Chemistry of Natural Compounds. 2013. Vol. 49, N5. Pp. 969-971.

7. Красильникова Л.А, Авксентьева О.А., Жмурко В.В., Садовниченко Ю.А. Биохимия растений : учеб. пособие. Ростов н/д, 2004. 224 с.

8. Lu D., Zhang S., Li H., Dai Y. Separation of glycyrrhetic acid monoglucuronide from glycyrrhizin hydrolysates by macroporous resins // Journal of Biotechnology. 2008. Vol. 136. Pp. 472-473.

9. Bombardelli E., Curd S.B., Della L.R., Del N.P., Tubaro A., Gariboldi P. Anti-inflammatory activity of 18-[beta]glycyrrhetinic acid in Phytosome form // Journal Fitoterapia. 1989. Vol. 60. Pp. 29-37.

10. Akao T. Effects of glycyrrhizin and glycyrrhetic acid on the growth, glycyrrhizin $\beta$-D-glucuronidase and $3 \beta$ hydroxysteroid dehydrogenase of human intestinal bacteria // Journal Biological and Pharmaceutical Bulletin. 2000. Vol. 23, Is.1. Pp. 104-107.

11. Farese S., Kruse A., Pasch A., Dick B., Frey B.M., Uehlinger D.E., Frey F.J. Glycyrrhetinic Acid Food Supplementation Lowers Serum Potassium Concentration in Chronic Hemodialysis Patients // Journal Kidney International. 2009. Vol. 76, Iss.8. Pp. 877-884.

12. Shibata S.A. Drug over the millennia: Pharmacognosy, chemistry, and pharmacology of licorice // Journal Yakugaku Zasshi. 2000. Vol. 120, Iss. 10. Pp. 849-862.

13. Shi J., Xiao J., Wei D. Synthesis of biotinylated 18ß-glycyrrhetinic acid and its effect on tumor cells activity // Journal Medicinal Chemistry Research. 2009. Vol. 18, Pp. 538-544.

14. Kalaiarasi P., Kaviarasan K., Pugalendi K.V. Hypolipidemic activity of $18 \beta$-glycyrrhetinic acid on streptozotocininduced diabetic rats // European Journal of Pharmacology. 2009. Vol. 612. Pp. 93-97.

15. Lekar' A.V., Yakovishin L.A., Borisenko S.N. Vetrova E.V., Borisenko N.I. Complexation of antibiotic levomycetin (chloroamphenicol) with $\alpha$-hederin and hederasaponin c under the conditions of electrospray // Journal of Analytical Chemistry. 2011. Vol. 66, Iss.14. Pp. 1437-1440.

16. Lekar' A.V., Vetrova E.V., Borisenko N.I., Yakovishin L.A., Grishkovets V.I. Mass spectrometric study on plant glycosides molecular complexation with streptocid (sulfanylamide) // Russian Journal of Bioorganic Chemistry. 2012. Vol. 38, Iss.7. Pp. 749-752. 
17. Zhou X., Zhao L., Liu X., Li X., Jia F., Zhang Y., Wang Y. Antimycobacterial and synergistic effects of 18ßGlycyrrhetinic acid or glycyrrhetinic acid-30-piperazine in combination with isoniazid, rifampicin or streptomycin against mycobacterium bovis // Phytother. Res. 2012. Vol. 26. Pp. 253-258.

18. Борисенко С.Н., Лекарь А.В., Ветрова Е.В., Филонова О.В., Борисенко Н.И. Масс-спектрометрическое исследование процессов самоассоциации молекул глицирретиновой кислоты // Химия растительного сырья. 2015. № 1. C. 89-94.

Поступило в редакциию 24 декабря 2014 г.

После переработки 14 сентября 2015 г.

Borisenko S.N., Vetrova E.V., Lekar A.V., Filonova O.V., Borisenko N.I.* MASS SPECTROMETRY OF SUPRAMOLECULAR COMPLEXES OF GLYCYRRHETINIC ACID WITH ANTIBIOTICS STREPTOTSID

Institute of Physical and Organic Chemistry of Southern Federal University, Stachka Ave., 194/2, Rostov-on-Don, 344090 (Russia),e-mail: boni@ipoc.rsu.ru

One of most effective ways to increase the bioavailability of drug substances is their structural modification by formation of supramolecular structures with plant glycosides. Application of noncovalent complexes of drugs with plant glycosides, e.g., glycyrrhizic acid (GA), isolated from the roots of Glycyrrhiza glabra L., leads to a significant improvement of pharmacokinetic and pharmacodynamic parameters of drugs. Glycyrrhizic acid (GLA) is the aglycon of GA and has the same molecular skeleton. Also, GLA has own broad spectrum of biological activity. The aim of the work is to study the complexation of GLA with antimicrobial drugs to create new low-dose pharmaceutical substances. In the present study, for the first time complex compounds of GLA and antibiotic sulfanilamide (Strep) were synthesized at different ratios «host» and «guest». The composition of supramolecular complexes of GLA with Strep was identified by mass spectrometry electrospray ionization. Peaks of heterogeneous complexes consisting of monomers, dimers, trimers and tetramers of GLA with the inclusion of one molecule of Strep were registered in mass spectra. The mass spectrometric data was shown high activity of the binding Strep by GLA with formation of supramolecular complexes. Given the high biological activity of GLA and possible synergies of heterogeneous complexes, research results open up prospects to obtain new low-dose drugs of Strep.

Keywords: glycyrrhetinic acid, glycyrrhizic acid, streptocid (sulfanilamide), mass spectrometry, electrospray ionization, complexation, supramolecular complexes.

\footnotetext{
* Corresponding author.
} 


\section{References}

1. Tolstikov G.A., Baltina L.A., Shults E.E., Pokrovskii A.G. Bioorganicheskaia khimiia, 1997, vol. 23, no. 9, pp. 691-703. (in Russ.).

2. Tolstikova T.G., Tolstikov A.G., Tolstikov G.A. Vestnik Rossiiskoi akademii nauk, 2007, vol. 77, no. 10, pp. 867-874. (in Russ.).

3. Stonik V.A., Tolstikov G.A. Vestnik Rossiiskoi akademii nauk, 2008, vol. 78, no. 8, pp. 675-684. (in Russ.).

4. Tolstikova T.G., Sorokina I.V., Bryzgalov A.O., Lifshits G.I., Khvostov M.V. Biomeditsina, 2006, vol. 1, no. 4, pp. 115-116. (in Russ.).

5. Borisenko S.N., Lekar' A.V., Milov A.A., Vetrova E.V., Borisenko N.I. Khimiia rastitel'nogo syr'ia, 2013, no. 2, pp. 85-92. (in Russ.).

6. Borisenko S.N., Lekar A.V., Vetrova E.V., Borisenko N.I. Chemistry of Natural Compounds, 2013, vol. 49, no. 5, pp. 969-971.

7. Krasil'nikova L.A, Avksent'eva O.A., Zhmurko V.V., Sadovnichenko Iu.A. Biokhimiia rastenii. [Plant Biochemistry]. Rostov-on-Don, 2004, 224 p. (in Russ.).

8. Lu D., Zhang S., Li H., Dai Y. Journal of Biotechnology, 2008, vol. 136, pp. 472-473.

9. Bombardelli E., Curd S.B., Della L.R., Del N.P., Tubaro A., Gariboldi P. Journal Fitoterapia, 1989, vol. 60, pp. $29-37$.

10. Akao T. Journal Biological and Pharmaceutical Bulletin, 2000, vol. 23, no. 1, pp. 104-107.

11. Farese S., Kruse A., Pasch A., Dick B., Frey B.M., Uehlinger D.E., Frey F.J. Journal Kidney International, 2009, vol. 76, no. 8, pp. 877-884.

12. Shibata S.A. Journal Yakugaku Zasshi, 2000, vol. 120, no. 10, pp. 849-862.

13. Shi J., Xiao J., Wei D. Journal Medicinal Chemistry Research, 2009, vol. 18, pp. 538-544.

14. Kalaiarasi P., Kaviarasan K., Pugalendi K.V. European Journal of Pharmacology, 2009, vol. 612, pp. $93-97$.

15. Lekar' A.V., Yakovishin L.A., Borisenko S.N. Vetrova E.V., Borisenko N.I. Journal of Analytical Chemistry, 2011, vol. 66, no. 14, pp. 1437-1440.

16. Lekar' A.V., Vetrova E.V., Borisenko N.I., Yakovishin L.A., Grishkovets V.I. Russian Journal of Bioorganic Chemistry, 2012, vol. 38, no. 7, pp. 749-752.

17. Zhou X., Zhao L., Liu X., Li X,. Jia F., Zhang Y., Wang Y. Phytother. Res., 2012, vol. 26, pp. 253-258.

18. Borisenko S.N., Lekar' A.V., Vetrova E.V., Filonova O.V., Borisenko N.I. Khimiia rastitel'nogo syr'ia, 2015, no. 1, pp. 89-94. (in Russ.). 